\title{
Influência de variáveis meteorológicas na produção de liteira na Estação Científica Ferreira Penna, Caxiuanã, Pará
}

\author{
Rosecélia Moreira da SILVA¹, José Maria Nogueira da COSTA², Maria de Lourdes Pinheiro RUIVO³, Antonio \\ Carlos Lôla da COSTA ${ }^{4}$, Samuel Soares ALMEIDA ${ }^{5}$
}

\begin{abstract}
RESUMO
A avaliação da influência da exclusão da precipitação sobre a variação na produção de liteira foi realizada na Reserva Florestal de Caxiuanã - Estação Científica Ferreira Penna (1 42' S, 51 31' W) durante o período de março de 2001 a fevereiro de 2003, com o objetivo de identificar as principais variáveis meteorológicas e do balanço hídrico mensal que afetaram a produção e decomposiçāo de liteira. Este trabalho foi parte do subprojeto EXPERIMENTO DE SECA NA FLORESTA (ESECAFLOR), que tinha o objetivo de estudar o impacto de seca prolongada na floresta nos fluxos de água, energia e dióxido de carbono na floresta amazônica. A sazonalidade na produção de liteira e de seus componentes (folhas, gravetos e partes reprodutivas) foi bem estabelecida, com a ocorrência da maior produção de liteira nos meses com menor precipitação. A produção total mensal de liteira variou durante o período experimental, de 294,78 kg.ha-1 a 1758,69 kg.hä ${ }^{-1}$, com um valor médio de 777,70 $\mathrm{kg} \cdot \mathrm{ha}^{-1}$. A produção total de liteira foi distribuída em folhas $(61,40 \%)$, gravetos $(18,45 \%)$ e partes reprodutivas $(20,14 \%)$. Os resultados obtidos na parcela sob condições naturais apresentaram uma maior produção de liteira, aproximadamente 25 \%, comparada com a produção de liteira na parcela submetida à exclusão da água de chuva. As variáveis mais fortemente correlacionadas com a produção de liteira e suas componentes foram a velocidade do vento, a densidade de fluxo de radiação solar global, a densidade de fluxo de radiação fotossintéticamente ativa, a temperatura do solo a $5 \mathrm{~cm}$ de profundidade, a precipitação, o déficit hídrico e o excesso hídrico.
\end{abstract}

PALAVRAS-CHAVE: Liteira, Floresta Amazônica, Decomposição, Variáveis Meteorológicas, deficiência hídrica.

\section{Influence of meteorological variables in the litterfall production in the Fer- reira Penna Scientific Station, Caxiuanã, Pará, Brazil}

\section{ABSTRACT}

The evaluation of the influence on the exclusion of rainfall on the variation of litter production was done in Caxiuanã Forest Reserve at Ferreira Penna Scientific Station (10 $42^{\prime}$ S, 51 $31^{\prime}$ W) during the period from March, 2001 to February, 2003 with the objective of identifying the main meteorological variables and the main components of the monthly water balance that affected the production and decomposition of litter. This work was part of the subproject EXPERIMENT OF DROUGHT IN THE FOREST (ESECAFLOR), that aimed to study the long term impacts of drought on the water, energy and carbon dioxide fluxes in the Amazon forest. The sazonality of total litter production and its components (leaves, brushwood and reproductive parts) was well established, with the occurrence of a greater litter production during the months with lower precipitation. The monthly litter production during the experimental period ranged from $294.78 \mathrm{~kg}$.ha- ${ }^{-1}$ to $1758.69 \mathrm{~kg} \cdot \mathrm{ha}^{-1}$, with an average of $777.70 \mathrm{~kg} \cdot \mathrm{ha}^{-1}$. The total litter production was partitioned in leaves $(61.40 \%)$, brushwoods $(18.45 \%)$ and reproductive parts $(20.14 \%)$. The results obtained in the undisturbed plot showed a higher litter production, about $25 \%$, compared to the litter production in the plot under the exclusion of water. The variables more strongly correlated with litter production and its components were wind speed, global solar radiation density flux, photosynthetic active radiation density flux, soil temperature at $5 \mathrm{~cm}$ depth, precipitation, soil water deficit and water surplus.

KEY WORDS: Litter, Amazon Forest, Decomposition, Meteorological Variables, water deficit.

\footnotetext{
1 Universidade Federal Rural da Amazônia. E-mail: rmsilva@museu-goeldi.br

2 Universidade Federal de Viçosa. E-mail: jmncosta@ufv.br

${ }^{3}$ Museu Paraense Emílio Goeldi. E-mail: ruivo@museu-goeldi.br

${ }^{4}$ Universidade Federal do Pará. E-mail: Iola@ufpa.br

${ }^{5}$ Museu Paraense Emílio Goeldi. E-mail: samuel@museu-goeldi.br
} 


\section{INTRODUÇÃO}

A quantidade do material vegetal que se deposita no solo resulta dos componentes senescentes da parte aérea das plantas, que ao caírem sobre o solo forma uma camada denominada liteira, que compreende as folhas, caules, flores e frutos (Golley, 1978). É por meio dos mecanismos de transferência entre a vegetação e o solo que ocorrem os processos de grande importância na nutrição e na sustentabilidade de florestas que crescem em solos pobres em nutrientes, como as florestas de região tropical.

A manutenção do ecossistema florestal na região tropical é muito dependente da ciclagem de nutrientes presentes na matéria orgânica, pois a maioria dos solos é altamente intemperizada e o estoque de nutrientes é relativamente baixo (Novais \& Barros, 1997). Nessa região, a liteira é um importante reservatório de carbono e constitui a principal via de

retorno de nutrientes ao solo (Silva, 1982). Estas formas de transferências que ocorrem entre a vegetação e o solo pode ter importante papel na floresta por influenciar no crescimento das espécies vegetais.

Com o crescimento e o aumento da idade das árvores, inicia-se a queda de folhas, gravetos e partes reprodutivas para a formação da camada de liteira, sendo que sua decomposição e liberação de nutrientes constituem os principais processos dos ciclos biogeoquímicos. A quantidade de liteira depositada pode variar dentro de um mesmo tipo de vegetação. Segundo (Werneck et al., 2001) a maioria dos ecossistemas florestais apresentam produção contínua de liteira durante todo o ano, sendo que a quantidade total produzida nas diferentes épocas depende do tipo de vegetação estudada (Leitão Filho et al.,1993).

Estudos tem demonstrado que as quantidades totais de liteira produzida em florestas tropicais no Brasil variam de 2,39 t.ha ${ }^{-1}$ (Neto, 2001) a 9,9 t.ha ${ }^{-1}$ (Franken et al., 1979), e em outros países de 2,1 tha ${ }^{-1}$ (Sanchez - Alvarez \& Sada, 1993) a 11,3 t.ha-1 (Golley, 1978).

Uma série de fatores bióticos e abióticos influenciam na produção de liteira, como: latitude, altitude, temperatura do ar, precipitação, estágio sucessional, herbivoria, disponibilidade hídrica e estoque de nutrientes do solo (Portes et al., 1996), umidade do solo (Burghouts et al.,1994) e vento (Dias \& Oliveira Filho, 1997).

A quantidade e a qualidade da liteira produzida têm importante função no processo de decomposição e do ciclo de nutrientes. $\mathrm{O}$ estudo sobre produção e decomposição de liteira é importante para se entender o funcionamento e a dinâmica dos ecossistemas florestais. A partir da associação de variáveis meteorológicas com a produção e decomposição de liteira, pode-se, por exemplo, investigar o comportamento da floresta sob estresse hídrico.

Vários pesquisadores argumentam que a quantidade total de liteira produzida e suas componentes, como queda de folhas, gravetos e elementos reprodutivos, assim como a velocidade de decomposição poderão ser afetadas quando estiverem sob estresse hídrico, o que, conseqüentemente, também poderá afetar outros mecanismos do ciclo de água, carbono e nutrientes.

Para comprovar essa hipótese, este estudo teve como objetivos avaliar a influência da exclusão de água da chuva sobre a variação da produção de liteira; identificar as principais variáveis meteorológicas e do balanço hídrico mensal que influenciam na variação da produção de liteira; estabelecer relações de dependência entre a produção de liteira e suas componentes com as variáveis meteorológicas e do balanço hídrico mensal mais fortemente correlacionado.

\section{MATERIAL E MÉTODOS}

A área de estudo está localizada no sítio experimental do Projeto LBA-ESECAFLOR na Reserva Florestal de Caxiuanã, Estação Científica "Ferreira Penna" (ECFPn), que ocupa uma área física de 33.000 ha dentro dos 330.000 ha da floresta Nacional de Caxiuanã ( $\left.1^{\circ} 42^{\prime} \mathrm{S}, 51^{\circ} 31^{\prime} \mathrm{W}\right)$ (Lisboa et al., 1997). Esta área está localizada no município de Melgaço, Pará, 400 km da cidade de Belém, no Nordeste da Amazônia. Os ambientes da floresta são de áreas de terra firme, várzea e igapó, porém 95\% da área abrange ambiente de terra firme (Lisboa et al.,1997). Este ambiente apresenta uma arquitetura florestal constituída de árvores emergentes (40 a $50 \mathrm{~m})$, dossel (30 a $35 \mathrm{~m}$ ), subdossel ( $20 \mathrm{a} 25 \mathrm{~m}$ ). A floresta apresenta diversidade considerável e grandes árvores, como o angelim- vermelho (Dinizia excelsa), Angelim-rajado (Marmaroxylon racemosum), tauari (Couratari guianensis), tanimbuca (Bucheniavia grandis), pitaíca (Swartzia racemosa), cumaru (Dipteryx odorata) dentre outras. Os solos são Latossolos Amarelos de origem terciária, com textura argiloarenosa, ácidos, profundos e oligotróficos (Almeida et al., 1993). A região de Caxiuanã se desenvolveu em um baixo planalto formado durante o período Cretáceo (Kern, 1996).

O clima da região é caracterizado como tropical úmido, do tipo Ami, segundo a classificação de Köppen (Moraes et al., 1997). As temperaturas médias mais baixas ocorrem de janeiro a março, enquanto os meses mais quentes são outubro a dezembro, com temperatura média de $27^{\circ} \mathrm{C}$. A temperatura média anual do ar é de $26^{\circ} \mathrm{C}$ e a umidade relativa média anual é de aproximadamente $80 \%$. A direção do vento predominante é de nordeste. 


\section{METODOLOGIA DO EXPERIMENTO ESECAFLOR}

O presente trabalho é parte do subprojeto ESECAFLOR, que visa estudar o impacto da seca prolongada nos fluxos de água e dióxido de carbono em uma floresta tropical amazônica (ESECAFLOR). Esse subprojeto investiga a influência da exclusão de água de chuva no solo sobre os ciclos de massa e de energia da floresta, simulando o fenômeno El Niño. Em sua estrutura física o ESECAFLOR foi constituído de duas (2) parcelas de 1 (um) hectare cada, dividido em 16 parcelas (sub-parcelas) de $25 \times 25 \mathrm{~m}$ cada. Na parcela experimental, foi feito a exclusão de aproximadamente $90 \%$ da água da chuva. A exclusão da água da chuva neste experimento foi feita com a utilização de 5.000 painéis plásticos coletores de água (Figura 1), instalados a uma altura de $1,5 \mathrm{a} 4 \mathrm{~m}$ acima do solo, calhas de drenagem e abertura de 8 trincheiras de $100 \mathrm{~m}$ de comprimento, por $1 \mathrm{~m}$ de largura e $2 \mathrm{~m}$ de profundidade. Essas trincheiras foram abertas no solo para impedir o movimento lateral da água. A outra parcela (parcela em condiçōes naturais) foi mantida como controle experimental.

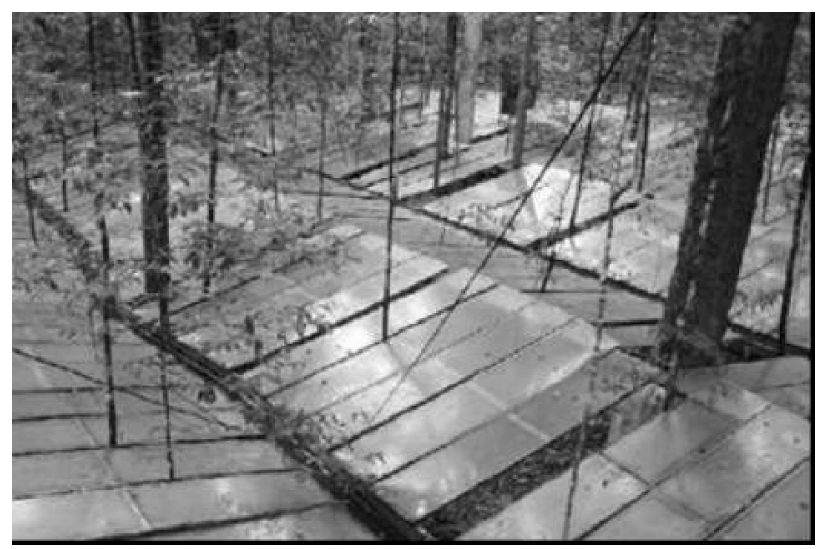

Fonte: Costa, A.C.L. (Disponível em: <http://www.geocities.yahoo.com.br/ esecaflor/)

Figura 1 - Vista parcial do Experimento ESECAFLOR, painéis cobrindo a superfície do solo.

\section{EXPERIMENTO DE COLETA DE QUEDA DE LITEIRA}

A liteira produzida pela floresta foi coletada, no período de março 2001 a fevereiro 2003, nas duas parcelas (A e B), pelo método das armadilhas para recolher detritos vegetais (litter trap). A partir de dezembro de 2001, foram instalados os painéis para que houvesse a exclusão de água da chuva. Foram utilizados em cada área, 20 coletores de formato circular, totalizando 40 coletores.

O coletor utilizado para este experimento (Figura 2) é de forma circular, com área de $1 \mathrm{~m}^{2}$, em base de arame galvanizado e tela de náilon de $2 \mathrm{~mm}$ de malha, sendo as bordas de arame galvanizado com telas de fio de náilon. A malha utilizada evita que a água da chuva fique parada, facilitando assim o escoamento para o solo, minimizando o escoamento da água, e a deterioração do material vegetal. $\mathrm{O}$ experimento foi implantado dentro de duas parcelas de 1 hectare cada (100 x $100 \mathrm{~m}, 10.000 \mathrm{~m} 2)$ (parcelas A e B). No experimento de coleta de queda de liteira foram sorteadas aleatoriamente 20 quadras (sub-parcelas) de $10 \times 10 \mathrm{~m}$ dentro de cada parcela.

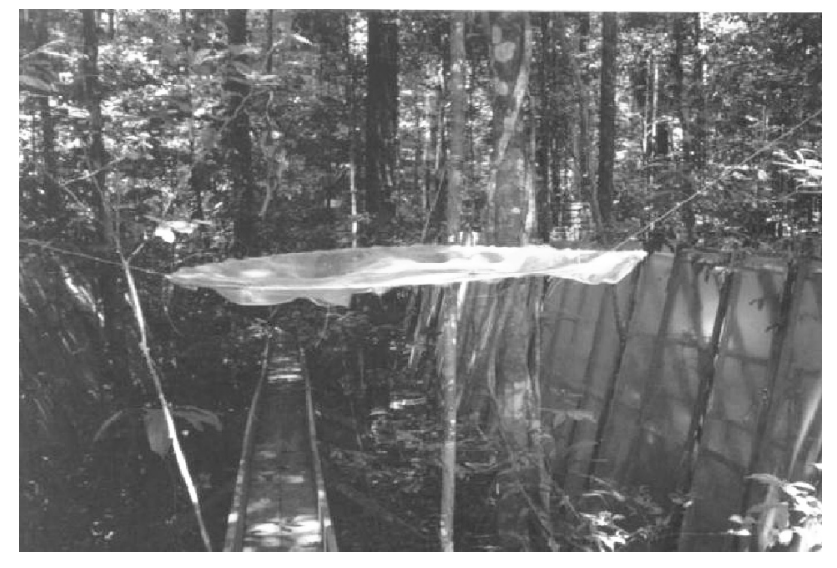

Figura 2 - Coleta de liteira, coletor $40 \mathrm{~cm}$ acima do solo.

No centro de cada parcela sorteada foram colocados os coletores a altura de aproximadamente $40 \mathrm{~cm}$ acima do solo, os quais foram suspensos por três piquetes de madeira. A partir do período de instalação dos painéis, os coletores foram suspensos acima dos painéis, para ser feita a coleta de liteira. Cada coletor foi identificado por uma numeração, onde foi realizado o inventário florestal.

\section{COLETAS DO MATERIAL DE CAMPO}

As coletas do material na floresta foram realizadas mensalmente. Para se retirar o material dos coletores, o seguinte procedimento foi utilizado: foram recolhidas manualmente todas as fraçôes da liteira total dos coletores, limpando-se toda a tela; em seguida, foram colocados em sacos de papel, e posteriormente em sacos plásticos, bem acondicionado para serem levados ao laboratório do campo experimental. No laboratório experimental, os sacos plásticos e de papel foram abertos e a água acumulada sobre as folhas foi escoada para secar primeiramente em condiçōes ambientais. Se fosse necessário, o material era colocado em uma estufa com lâmpadas acesas $\left(40-60^{\circ} \mathrm{C}\right)$ por um período de 24 a 36 horas até ser levado ao laboratório para a secagem completa em estufa.

No laboratório de Botânica do Museu Paraense Emílio Goeldi, o material vegetal foi colocado em novos sacos de papel para serem colocados em estufa a $80^{\circ} \mathrm{C}$, por um período de 48 horas, até obter peso constante. Após a secagem, o material foi separado nas fraçôes: 
a) foliar: Consistindo de folhas e estípulas; e

b) não foliar: Consistindo de flores, frutos, botôes, cascas e ramos finos $(\varnothing=1 \mathrm{~cm})$.

Em seguida, o material foi pesado em balança analítica de dois dígitos; a pesagem foi feita por coletor, por fração e por parcela.

\section{MEDIÇÕES DE CONTEÚDO DE ÁGUA NO SOLO}

Para as medidas de conteúdo de água no solo, foi aplicado a Técnica do TDR (Time-Domain Reflectometer). Usando um monitor Tektronic 1502B/C, com o WATTDR 3.11 software (Waterloo Centre for Groundwater Research). Em cada uma das parcelas A e B foram abertas quatro trincheiras com $1 \mathrm{~m}$ de largura, $2 \mathrm{~m}$ de comprimento e $5 \mathrm{~m}$ de profundidade. Nestes buracos foram instalados sensores, em perfis, a cada metro de profundidade, nos dois lados de menor dimensão, e realizadas medidas quinzenais regulares desde setembro de 2002.

\section{MEDIÇÕES METEOROLÓGICAS}

A plataforma de instalação dos instrumentos constituiuse de uma torre de alumínio com $55 \mathrm{~m}$ de altura, sendo os equipamentos mantidos por dois conjuntos de baterias, um com quatro e o outro com cinco baterias de $150 \mathrm{Ah} / 12 \mathrm{VDC}$, e por quatro painéis solares $(75 \mathrm{~W})$, cada um contendo três células fotovoltáicas.

Os dados meteorológicos referentes ao saldo de radiação, densidade de fluxo de radiação solar global, temperatura do ar, umidade do ar, precipitação, direção e velocidade do vento, umidade relativa do ar e densidade de fluxo de radiação fotossintéticamente ativa foram coletados continuamente acima do dossel das árvores. Foram registradas médias a cada 30 minutos, as quais foram armazenadas em um sistema de aquisição de dados (data logger) Campbell Scientific. Esses dados foram utilizados na elaboração do balanço hídrico mensal de acordo com o procedimento proposto por (Thornthwaite \& Mather, 1955), citado por (Vianello \& Alves, 1991). Os componentes do balanço de água no solo foram posteriormente relacionados com os dados de produção e decomposição de liteira usando-se técnicas de análise de regressão.

\section{ANÁLISE DE CORRELAÇÃO E DE REGRESSÃO}

O coeficiente de correlação de Pearson foi usado na determinação das correlaçôes entre a produção total de liteira e suas componentes com as variáveis meteorológicas e do

balanço hídrico mensal, conforme equação 1 :

$$
r=\frac{\sum(x-\bar{x})(y-\bar{y})}{\sqrt{\sum(x-\bar{x})^{2} \cdot \sum(y-\bar{y})^{2}}}
$$

em que: $x=$ variável meteorológica ou do balanço hídrico mensal;

$\bar{x}=$ média de $\mathrm{x} ;$

$y=$ produção mensal total de liteira ou de suas componentes (folhas, gravetos e partes reprodutivas);

$\overline{\mathrm{y}}=$ média de $\mathrm{y}$

$r$ = coeficiente de correlação entre a produção total de liteira (ou de suas componentes) e de cada variável meteorológica ou do balanço hídrico mensal analisado.

Análises de regressão linear foram utilizadas para se avaliar a influência de uma única variável, meteorológica ou do balanço hídrico mensal, na produção total de liteira ou de suas componentes (folhas, gravetos e partes reprodutivas). As análises de correlação e de regressão foram feitas usando-se o programa SPSS for Windows (SPSS, 1999).

\section{RESULTADOS E DISCUSSÃO}

Observa-se na Figura 3, a variação mensal da produção total de liteira durante o período de março de 2001 a fevereiro de 2003 na parcela A. Produção mensal total de liteira na parcela A variou de 294,78 kg.ha ${ }^{-1}$ a 1758,69 kg.ha ${ }^{-1}$, com um valor médio de 777,70 $\pm 352,56 \mathrm{~kg} \cdot \mathrm{ha}^{-1}$. A sazonalidade da produção total de liteira foi bem evidenciada na parcela $A$ durante os 24 meses de coleta de dados, tendo sido constatado uma maior produção de liteira em junho de 2001, que é um mês típico de estação menos chuvosa, enquanto a menor produção de liteira ocorreu em janeiro de 2003, que representa um mês típico da estação chuvosa. Observou-se que os meses da estação menos chuvosa com maior produção de liteira foram junho, julho, agosto e setembro para os anos de 200 e 2002, enquanto os meses da estação chuvosa com menor produção de liteira foram janeiro, fevereiro, março e abril para os anos de 2001 e 2002.

A média mensal no primeiro ano de medições (março/2001 a fevereiro/2002) foi de $816,30 \pm 387 \mathrm{~kg} \cdot \mathrm{ha}^{-1}$ enquanto no período de março de 2002 a fevereiro de 2003 foi de 739,10 $\pm 327 \mathrm{~kg} \cdot \mathrm{ha}^{-1}$, representando um valor total para o primeiro período de 9,79 t.ha ${ }^{-1}$.ano ${ }^{-1}$ e de 8,87 t.ha $^{-1}$.ano $o^{-1}$ para o segundo período.

Na parcela B, a produção total de liteira (Figura 4) variou de 329,74 kg.ha- ${ }^{-1}$ a 1.010,99 kg.ha-1 ${ }^{-1}$ com um valor médio de $551,47 \pm 167,04 \mathrm{~kg} \cdot \mathrm{ha}^{-1}$. A maior produção total de liteira ocorreu em julho de 2002 (um mês típico da estação menos chuvosa) e a menor produção total de liteira ocorreu em janeiro de 2003 (um mês típico da estação chuvosa).

A comparação entre a produção total de liteira nas duas parcelas estudadas, considerando apenas o período de exclusão da chuva na parcela B (dezembro/2001 a fevereiro/2003), está apresentada na Figura 5. A produção total de liteira na 


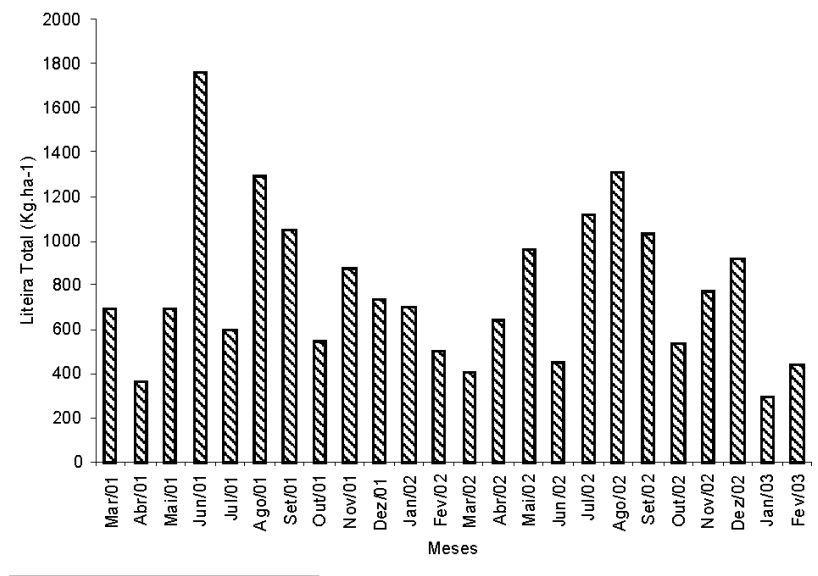

Figura 3 - Variação mensal da produção total de liteira na parcela A.

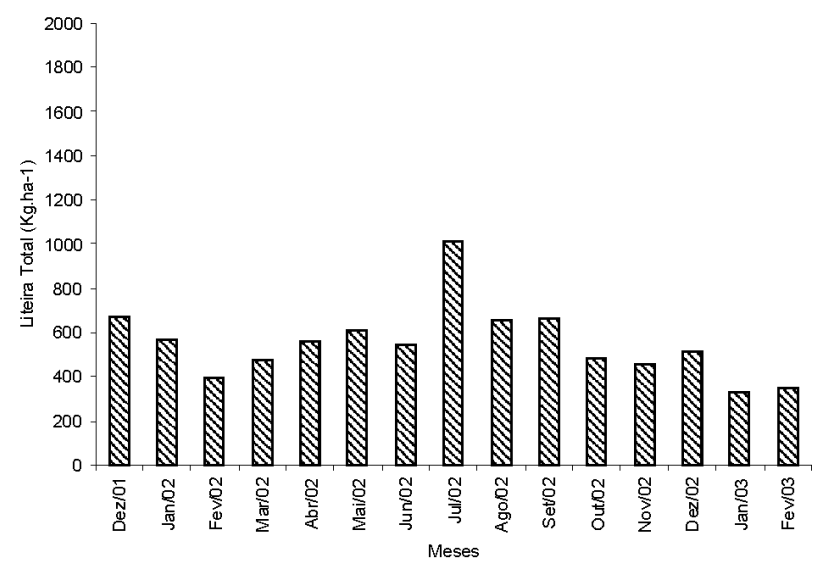

Figura 4 - Variação mensal da produção total de liteira na parcela B, no período de exclusão de chuva.

parcela A foi significativamente maior do que na parcela $\mathrm{B}$ em praticamente todo o período estudado (Teste $t, P<0,05$ ). Embora a sazonalidade na parcela $B$ também tenha sido constatada, como pode ser observado pela diferença entre os valores máximos e mínimos, a influência da exclusão da água nessa parcela, com conseqüente maior deficiência hídrica em relação à parcela $\mathrm{A}$, resultou em menor queda de liteira nessa parcela comparada com os valores obtidos na parcela $\mathrm{A}$.

A produção média mensal de liteira no período de março/2002 a fevereiro/2003 foi de 553,36 $\pm 178,70 \mathrm{~kg} \cdot \mathrm{ha}^{-1}$, correspondendo a um total de 6,64 t.ha $^{-1} \cdot$ ano $^{-1}$, indicando uma redução da ordem de aproximadamente $25 \%$ em relação à produção de liteira na parcela A no mesmo período.

A variação mensal das contribuições de folhas, gravetos e partes reprodutivas para a produção total de liteira nas parcelas A e B está ilustrada nas Figuras 6 e 7, respectivamente. A contribuição das folhas na produção total de liteira foi a mais importante nas duas parcelas (A e B). A queda mensal de folhas apresentou um valor médio de 548,50 \pm 334,61

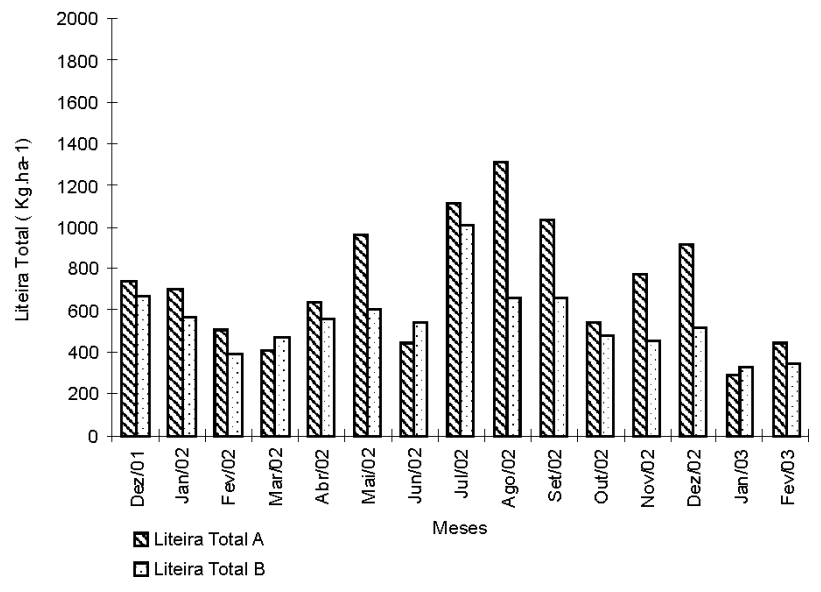

Figura 5 - Produção mensal de liteira, na parcela A e B, no período de exclusão de chuva.

kg.ha ${ }^{-1}$ no período de março de 2001 a fevereiro de 2002 e de 466,38 $\pm 269,93 \mathrm{~kg} \cdot \mathrm{ha}^{-1}$ no período de março de $2002 \mathrm{a}$ fevereiro de 2003, na parcela A. Os picos de produção de folhas ocorreram em junho de 2001 e julho de 2002, meses típicos da estação menos chuvosa. Os menores valores de queda de folhas ocorreram em abril de 2001 e janeiro de 2003, que são meses típicos de estação chuvosa. A contribuição de gravetos na produção de liteira foi em média de 133,36 $\pm 65,29 \mathrm{~kg} \cdot \mathrm{ha}^{-1}$ no período de março de 2001 a fevereiro de 2002 e de 120,85 $\pm 49,23 \mathrm{~kg} \cdot \mathrm{ha}^{-1}$ no período de março de $2002 \mathrm{a}$ fevereiro de 2003, na parcela A.

As partes reprodutivas apresentaram um valor médio de $134,43 \pm 80,54 \mathrm{~kg} \cdot \mathrm{ha}^{-1}$ no período de março de $2001 \mathrm{a}$ fevereiro de 2002 e de $151,87 \pm 107,90 \mathrm{~kg} \cdot \mathrm{ha}^{-1}$ no período de março de 2002 a fevereiro de 2003.

A média mensal de queda de folhas, produção de gravetos e partes reprodutivas na parcela B foram respectivamente de $405,97 \pm 196,86 \mathrm{~kg} \cdot \mathrm{ha}^{-1}, 96,11 \pm 20,97 \mathrm{~kg} \cdot \mathrm{ha}^{-1}$ e $51,29 \pm$ $38,84 \mathrm{~kg} \cdot \mathrm{ha}^{-1}$ no período de março de 2002 a fevereiro de 2003. Com a maior quantidade de produção de folhas em julho de 2002, evidencia a produção de liteira total maior para o mesmo período.A produção de gravetos e partes reprodutivas foram semelhantes durante todo o período, com uma produção anual estável.

A contribuição relativa em percentagem de folhas, gravetos e partes reprodutivas na produção total de liteira está ilustrada nas Figuras 8 e 9 para as parcelas A e B, respectivamente. A contribuição média das folhas, gravetos e partes reprodutivas na produção total de liteira foi respectivamente de $65,98 \%$, $16,48 \%$ e $17,54 \%$ para a parcela A no período de março de 2001 a fevereiro de 2002. No período de março de 2002 a fevereiro de 2003 na parcela A, a contribuição de folhas, 


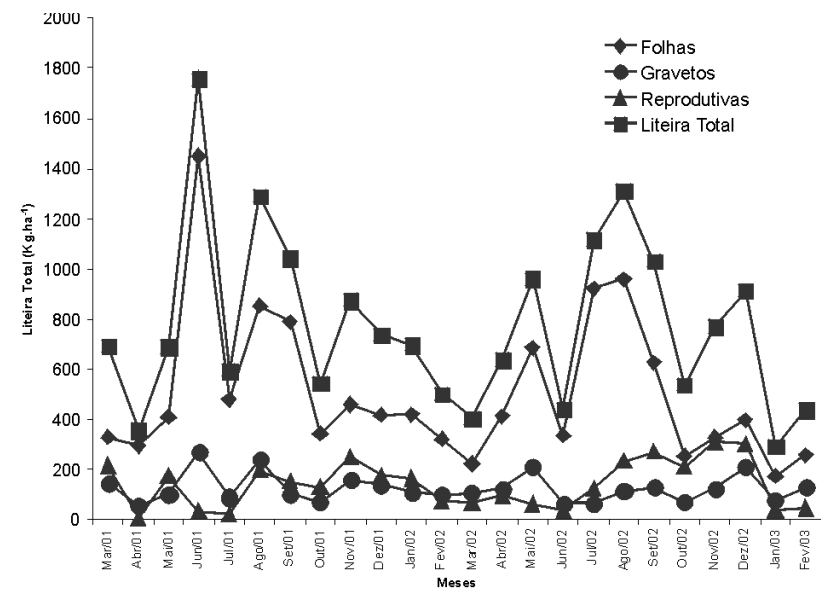

Figura 6 - Produção mensal de liteira e a sua partição em folhas, gravetos e partes reprodutivas na parcela $A$

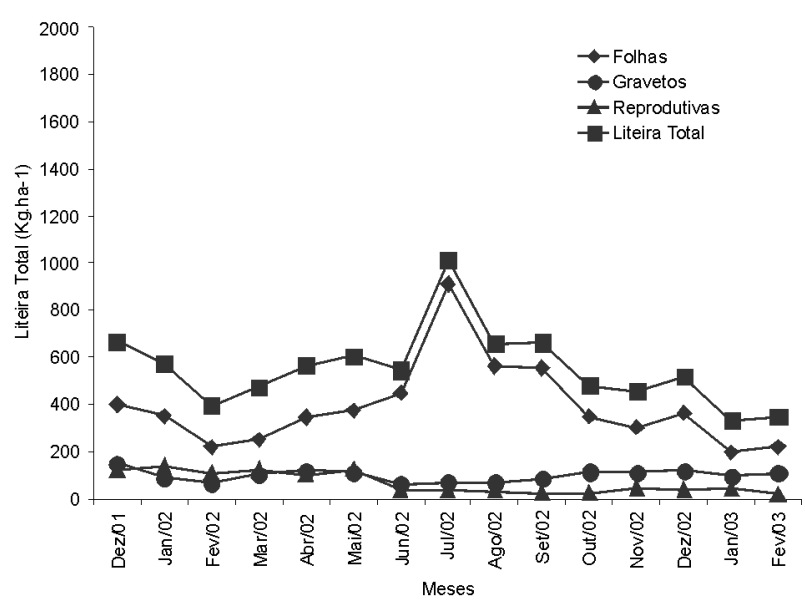

Figura 7 - Produção mensal de liteira e a sua partição em folhas, gravetos e partes reprodutivas na parcela $B$.

gravetos e partes reprodutivas na produção total de liteira foi respectivamente de $61,40 \%, 18,45 \%$ e de $20,14 \%$.

No período de março de 2002 a fevereiro de 2003, na parcela $\mathrm{B}$, as folhas, gravetos e partes reprodutivas contribuíram, respectivamente em média, com $70,83 \%$, $19,33 \%$ e $9,84 \%$ da produção total de liteira. Na parcela B, a contribuição de folhas e de gravetos na produção total de liteira foi maior na parcela A.

Os resultados encontrados referentes a produção de liteira na parcela controle são superiores aos encontrados por Luizão (1982) sobre produção de liteira em floresta de terra firme da Amazônia Central em Manaus, em uma área de platô $(7,42$ t.ha ${ }^{-1} \cdot$ ano $\left.^{-1}\right)$, uma área de baixio $\left(6,48\right.$ t.ha $^{-1} \cdot$ ano $\left.^{-1}\right)$ e uma área de capoeira $\left(6,07\right.$ t.ha $^{-1} \cdot$ ano $\left.^{-1}\right)$. Mediçôes de liteira feitas por (Dantas e Phillipson, 1989) em floresta primária em Capitão Poço - PA, apresentaram médias de produção de 8,04 t.ha ${ }^{-1}$. ano $^{-1}$. Todavia mediçōes feitas por (Teixeira et al.,2001) nessa mesma localidade em floresta primária e secundária, produziram médias de 5,81 th.ha ${ }^{-1} \cdot$ ano $^{-1}$ e 3,83 tha ${ }^{-1} \cdot$ ano $^{-1}$, respectivamente.

(Silva, 1982) comparou a produção de liteira em floresta em diferentes ambientes, tendo constatado que a produção total de liteira em área de terra firme, área de várzea e área de

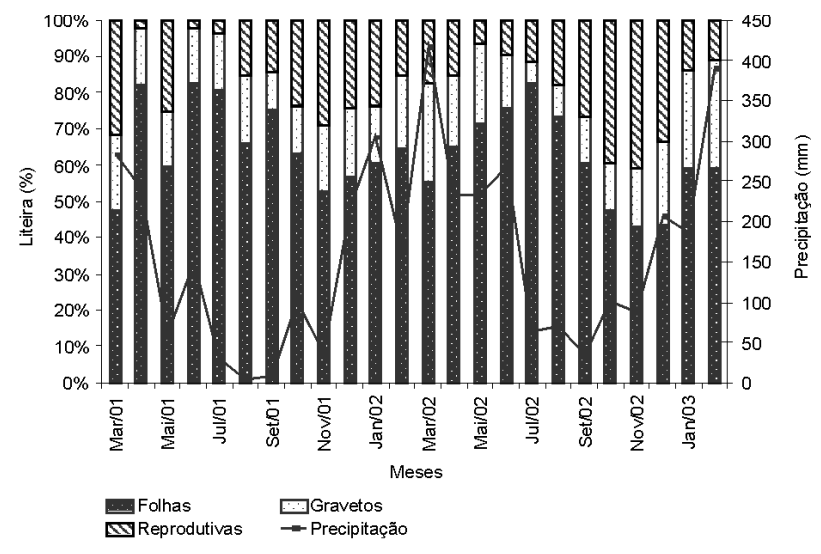

Figura 8 - Percentual mensal das frações da produção total de liteira na parcela $A$.

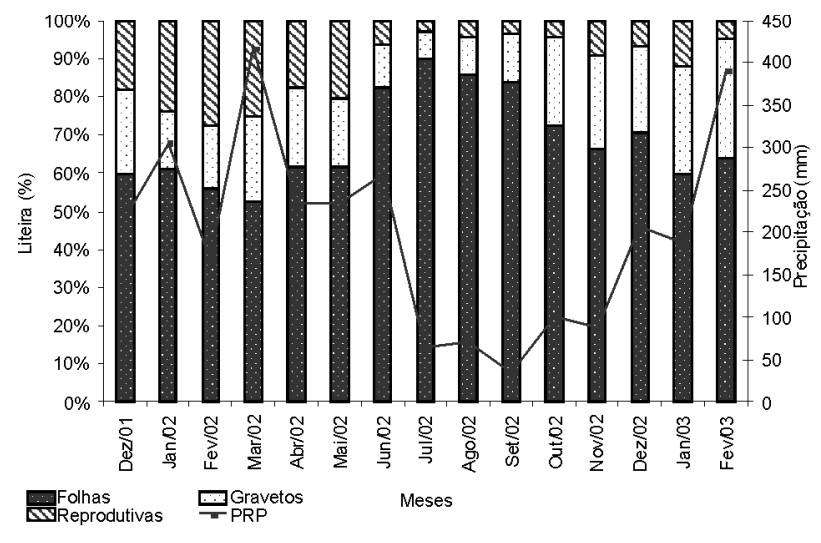

Figura 9 - Percentual das frações da produção de liteira na parcela B, no período de exclusão de chuva.

igapó, foram respectivamente de 7,3 t.ha ${ }^{-1} \cdot$ ano $^{-1}$; 3,6 t.ha ${ }^{-1}$. ano $^{-1}$ e 7,6 t.ha $^{-1} \cdot$ ano $^{-1}$. Resultados obtidos por Franken et al. (1979) sobre produção de liteira em floresta de terra firme em Belém foram de 9,9 t.ha ${ }^{-1}$.ano ${ }^{-1}$, bem semelhantes aos encontrados em nosso estudo.

Por outro lado a produção de liteira em floresta primária, em Manaus, foi inferior ao valor encontrado em Belém, tendo variado de 7,8 a 8,0 t.ha $^{-1}$.ano ${ }^{-1}$. A influência da sazonalidade na produção de liteira, também foi constatada na maioria dos 
trabalhos citados, nos quais a menor produção de liteira ocorreu na estação chuvosa e a maior na estação menos chuvosa.

As variáveis mais fortemente correlacionadas com a produção total de liteira foram, em ordem decrescente de magnitude, a temperatura do solo a $5 \mathrm{~cm}$ de profundidade, a densidade de fluxo de radiação solar global, a densidade de fluxo de radiação fotossintéticamente ativa, velocidade do vento, deficiência hídrica e precipitação.

Na Figura 10 observa-se que a precipitação apresentou uma correlação negativa com a produção total de liteira, o período que houve maior quantidade de chuva apresentou uma menor produção de liteira e vice-versa. A quantidade de folhas produzida foi maior que todas as fraçóes produzidas durante os 24 meses de coleta.

A Figura 11 mostra a radiação solar global durante o período de janeiro de 2001 a julho de 2002 com a produção

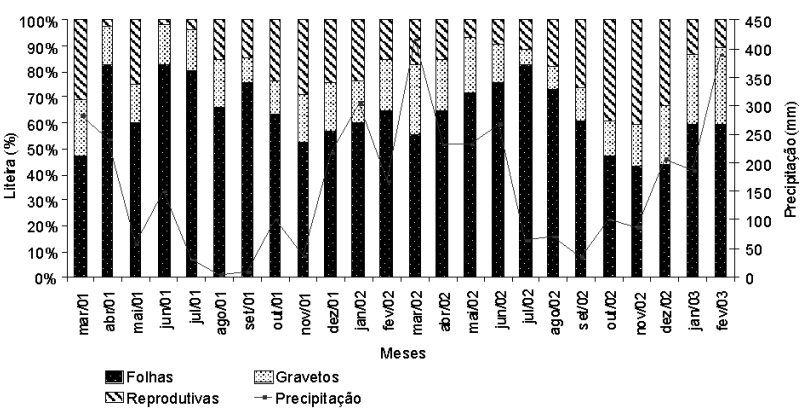

Figura 10 - Variação das frações totais de liteira e precipitação durante 0 periodo experimental.

total de liteira. Os meses de maio, julho, outubro e dezembro de 2001 e janeiro, fevereiro de 2002, apresentaram altos índices de densidade de fluxo de radiação solar global, correspondente aos anos de 2001, respectivamente (466,38 w. m-2 $, 509,42$ w.m $\mathrm{m}^{-2} ; 447,74$ w.m $\mathrm{m}^{-2}$ e 542,42 w.m $\left.\mathrm{m}^{-2}\right)$ e $2002\left(577,75\right.$ w.m $\mathrm{m}^{-2} \mathrm{e}$ 542,91 w. $\left.\mathrm{m}^{-2}\right)$ com períodos seco. Ocorreu grande produção de liteira $\left(1311,68 \mathrm{Kg} \cdot \mathrm{ha}^{-1}\right)$, comprovando que a produção de liteira é maior no período menos chuvoso.

A Figura 12 mostra a produção total de liteira e a densidade de fluxo de radiação PAR $\left(\mu \mathrm{mol} \cdot \mathrm{m}^{-2} \cdot \mathrm{s}^{-1}\right)$ durante o período de janeiro de 2001 a dezembro de 2002, onde o índice de radiação PAR foi maior $\left(867,49\right.$ umol. $\left.\mathrm{m}^{-2} . \mathrm{s}^{-1}\right)$ houve maior liteira produzida $\left(1758,68 \mathrm{Kg} \mathrm{ha}^{-1}\right)$, para os 24 meses de análises. A quantidade de folhas produzida aparentemente não foi influenciada pela densidade de fluxo de radiação PAR, por evidenciar variaçōes na produção de folhas durante todo o período. A relação entre densidade de fluxo de radiação PAR comparada com a produção de fraçôes reprodutivas foi semelhante com a relação entre densidade de fluxo de radiação PAR com a produção de folhas, apresentando maior índice de radiação PAR nos períodos de maior produção da liteira. O mês de janeiro de 2001 resultou

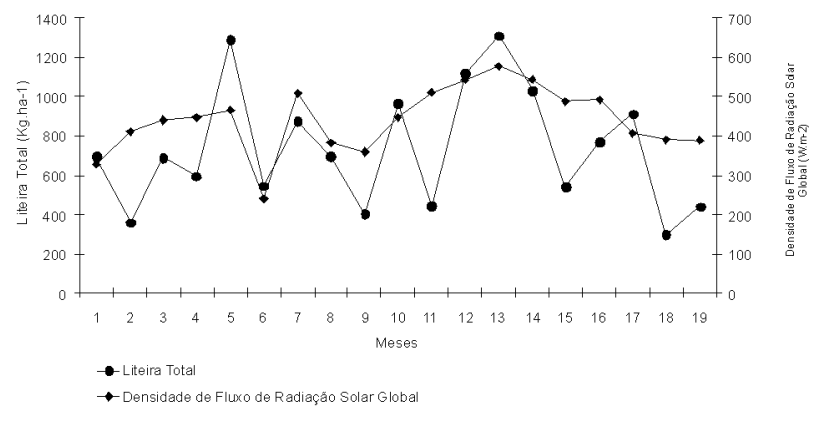

Figura 11 - Produção total de liteira e densidade de fluxo de radiação solar global durante o período experimental.

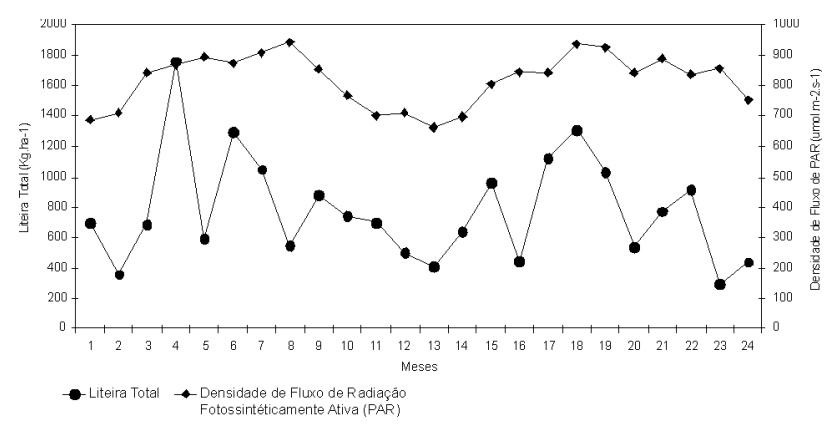

Figura 12 - Variação mensal da Produção total de liteira e da densidade de fluxo radiação fotossintéticamente ativa (PAR) durante o período experimental.

no mês de maior índice de radiação, de produção de folhas e fraçōes reprodutivas.

A Figura 13 mostra a produção total de liteira com a temperatura do solo a $5 \mathrm{~cm}$ de profundidade, mostrando que onde a temperatura foi elevada ocorreu maior produção de liteira. Todas as variáveis meteorológicas analisadas foram positivamente correlacionadas com a produção de folhas. A temperatura do solo permaneceu estável, não influenciando na produção de folhas que foi evidenciada durante todo o período experimental. A temperatura do solo não apresentou variação, não evidenciando ter influenciado na produção de gravetos, resultado semelhante na produção de folhas, que sofreu influencia na sua produção, havendo variação na produção durante todo o período experimental.

A queda de fraçóes reprodutivas acompanhou a mesma linha de tendência da velocidade do vento, apresentando a mesma variação nos meses correspondentes apresentando correlaçăo (Figura 14). Os meses de Janeiro, Março e Junho de 2001 apresentaram maior produção de frações reprodutivas e período que a velocidade do vento foi maior. Os meses de Fevereiro, Abril e Maio de 2001 a intensidade do vento foi menor e ocorreu menor produção de fraçōes reprodutivas. 


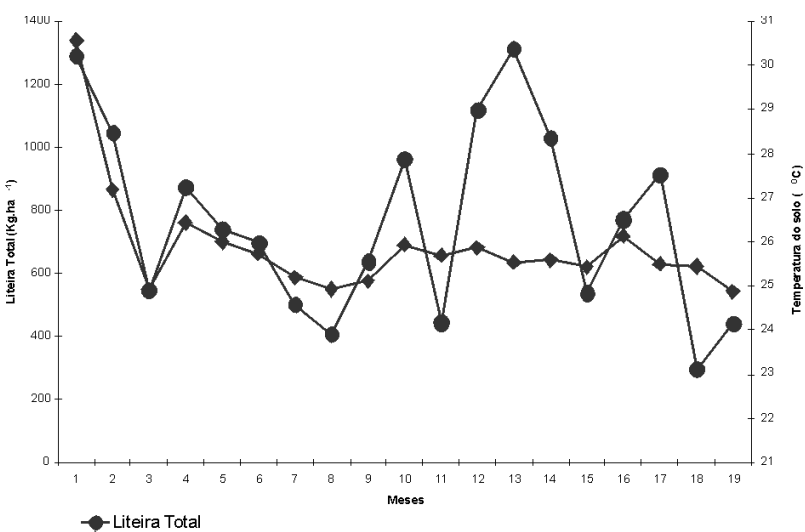

Figura 13 - Variação mensal da Produção total de liteira e da temperatura do solo a $5 \mathrm{~cm}$ de profundidade durante 0 período experimental.

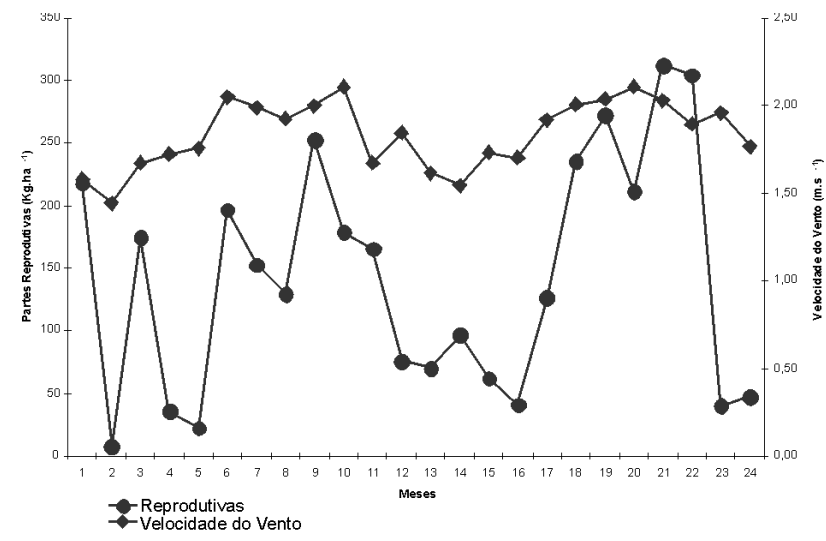

Figura 14 - Variação mensal da queda de partes reprodutivas e da velocidade do vento durante o período experimental.

As variáveis meteorológicas que mais influenciaram a queda de folhas, com base no coeficiente de correlação em ordem decrescente foram a densidade de fluxo de radiação solar global, a temperatura do solo a $5 \mathrm{~cm}$ de profundidade, a densidade de fluxo de radiação PAR e a umidade do solo.

Conforme a tabela 1 , todas essas variáveis meteorológicas foram positivamente correlacionadas com a queda de folhas. A maioria das variáveis analisadas apresentou valores de coeficiente de correlação muito baixos em relação à queda de gravetos, com exceção da temperatura do solo a $5 \mathrm{~cm}$ de profundidade, que foi positivamente correlacionada, e a deficiência hídrica, com um valor de coeficiente de correlação aproximadamente três vezes negativamente correlacionada com a queda de gravetos. A deficiência hídrica foi maior nos meses de janeiro a maio de 2001, outubro de 2001 a maio de 2002 e outubro a dezembro de 2002, a fração de partes reprodutivas produzida foi maior no mês de setembro de 2001 e setembro de 2002, que corresponderam a meses de pouca chuva com $9 \mathrm{~mm}$ e $35 \mathrm{~mm}$, respectivamente.

As maiores influências das variáveis meteorológicas e do balanço hídrico mensal nas partes reprodutivas foram a umidade do solo, a velocidade do vento, excedente hídrico, precipitação e deficiência hídrica.

Tabela 1 - Coeficientes de correlação entre os valores mensais de produção total de liteira e de seus componentes com variáveis meteorológicas e do balanço hídrico mensal.

\begin{tabular}{|c|c|c|c|c|}
\hline Variáveis & $\begin{array}{l}\text { Produção } \\
\text { Total de } \\
\text { Liteira }\end{array}$ & Folhas & Gravetos & $\begin{array}{c}\text { Partes } \\
\text { Reprodutivas }\end{array}$ \\
\hline Temperatura do ar & 0,16 & 0,18 & $-0,05$ & 0,05 \\
\hline Vento & 0,30 & 0,16 & 0,09 & $0,57^{\star *}$ \\
\hline Precipitação & $-0,20$ & $-0,08$ & 0,01 & $-0,49 *$ \\
\hline $\begin{array}{l}\text { Densidade de fluxo de } \\
\text { radiação solar global } \\
(\text { W.m²) }\end{array}$ & 0,56 & 0,59 & 0,05 & 0,29 \\
\hline $\begin{array}{l}\text { Densidade de fluxo } \\
\text { de radiação PAR } \\
\left(\mu \text { mol. } \mathrm{m}^{-2} \cdot \mathrm{s}^{-1}\right)\end{array}$ & $0,45^{\star}$ & $0,42^{*}$ & 0,06 & 0,32 \\
\hline $\begin{array}{l}\text { Temperatura do solo } \\
(5 \mathrm{~cm})\end{array}$ & 0,59 & 0,53 & 0,56 & 0,25 \\
\hline $\begin{array}{l}\text { Temperatura do solo } \\
(20 \mathrm{~cm})\end{array}$ & 0,04 & 0,02 & $-0,11$ & 0,16 \\
\hline Umidade do solo & $-0,002$ & 0,28 & $-0,09$ & $-0,65^{\star \star}$ \\
\hline $\begin{array}{l}\text { Evapotranspiração } \\
\text { potencial (ETP) }\end{array}$ & 0,19 & 0,21 & $-0,07$ & 0,08 \\
\hline Evapotranspiração real & $-0,01$ & 0,09 & $-0,17$ & $-0,23$ \\
\hline Deficiência hídrica & 0,27 & 0,14 & 0,19 & $0,46^{*}$ \\
\hline Excesso hídrico & $-0,11$ & 0,02 & 0,06 & $-0,51^{*}$ \\
\hline
\end{tabular}

* Correlação significativa ao nível de $5 \%$.

** Correlação significativa ao nível de $1 \%$.

A fração reprodutiva produzida foi maior onde o excesso hídrico foi maior, que correspondeu aos meses de período seco, que foram os meses de maio a outubro de 2001 e junho a outubro de 2002. Dentre as variáveis analisadas, a temperatura do ar, temperatura do solo a $20 \mathrm{~cm}$ de profundidade, a evapotranspiração potencial e a evapotranspiração real apresentaram baixos valores de coeficiente de correlação com a liteira total e seus componentes. Apenas algumas variáveis meteorológicas apresentaram maiores coeficientes de correlação em relação entre a produção total de liteira e suas componentes.

Os resultados das análises de regressão entre a produção total de liteira e suas componentes com as variáveis meteorológicas e do balanço hídrico mais fortemente correlacionado não resultaram em equaçóes preditivas satisfatórias sobre a produção de liteira. 


\section{CONCLUSÕES}

A sazonalidade da produção total de liteira e de suas componentes (folhas, gravetos e partes reprodutivas) foi bem evidenciada na Estação Científica Ferreira Penna, com a ocorrência de maior produção na estação menos chuvosa. A exclusão da água de chuva resultou em uma redução em torno de $25 \%$ na produção total de liteira. Conforme era esperado, a queda de folhas representou a mais importante contribuição na produção total de liteira. O percentual médio de contribuição das folhas, gravetos e partes reprodutivas na produção total de liteira foi de $65,98 \%, 16,48 \%$ e $17,54 \%$, respectivamente.

Dentre as variáveis meteorológicas que se mostraram mais correlacionadas com a produção total de liteira e, ou, suas componentes, destacaram-se a velocidade do vento, a temperatura do solo a $5 \mathrm{~cm}$ de profundidade, a densidade de fluxo de radiação solar global, a precipitação e a densidade de fluxo da radiação PAR.

Com relação às variáveis do balanço hídrico, as variáveis mais fortemente correlacionadas com a produção de liteira e, ou, suas componentes foram o teor de umidade do solo, o excesso hídrico e a deficiência hídrica. A análise de regressão entre a produção total de liteira e suas componentes com as variáveis meteorológicas e do balanço hídrico não apresentaram relaçôes de dependência entre si.

\section{AGRADECIMENTOS}

A Coordenação de Aperfeiçoamento de Pessoal de Nível Superior (CAPES), pela bolsa concedida ao curso de PósGraduação em Meteorologia Agrícola/ Universidade Federal de Viçosa/UFV, ao Museu Paraense Emílio Goeldi (MPEG), pela oportunidade das atividades de campo desenvolvidas.

\section{BIBLIOGRAFIA CITADA}

Almeida, S. S.; Lisboa, P. L. B.; Silva, A. S. L. 1993. Diversidade florística de uma comunidade arbórea na Estação Científica "Ferreira Penna", em Caxiuanã (Pará). Boletim do Museu Paraense Emílio Goeldi, Botânica, Belém, Vol. 9, n. 1, p. 99188.

Burghouts, T. B. A.; Campbell, E. J. F.; Koderman, P. J. 1994. Effects of tree species heteregeneity of leaf fall in primary an logged dipterocarp forest in the Ulu Segana Forest Reserv, Sabah, Malasia. Journal of Tropical Ecology, Vol. 10, p. 1-26.

Dantas, M.; Phillipson, J. 1989. Litterfall and nutrient content in primary and secondary Amazonian "terra firme" rain forest. Journal of Tropical Ecology, Vol. 5, p. 27-36.

Dias, H. C. T.; Oliveira Filho, A. T. 1997. Variação temporal e espacial da produção de liteira em uma área de Floresta Estacional Semidecídua Montana em Lavras-MG. Revista Árvore, Vol. 21, n. 1, p. 11-26.
Franken, M. E. H.; Irmler, U.; Klinge, H. 1979. Litterfall in inundation, riverini and terra

firme forest of Central Amazonia. Tropical Ecology, Vol. 20, p. 225-235.

Golley, F. B. 1978. Ciclagem de minerais em um ecossistema de floresta tropical úmida. Tradução de Eurípides Malavolta. EPU. Editora da Universidade de São Paulo.105 pp.

Kern, D. C. 1996. Geoquímica e pedoquímica em sítios arqueológicos com terra preta na Floresta Nacional de Caxiuanã (Portel - Pa). Tese de Doutorado - Universidade Federal do Pará, Belém, Pará. 119pp.

Leitão-Filho, H. F.; Pagano, S. N.; CÉSAR, O. ; Timoni, J. L.; Rueda, J.1993. Ecologia da Mata Atlântica em Cubatão. São Paulo: EDUSP, 184 pp.

Lisboa, P. L. B.; Silva, A. S. L.; Almeida, S. S. 1997. Florística e estrutura dos ambientes. In: LISBOA, P. L. B. (Org.). Caxiuanã. Museu Paraense Emílio Goeldi, Belém, Pará. p. 163-193.

Luizão, F. J. 1982. Produção e decomposição de liteira em floresta de terra firme da Amazônia Central. Aspectos químicos e biológicos da lixiviação e remoção dos nutrientes da liteira. Dissertação de Mestrado, Instituto Nacioal de Pesquisas da Amazônia/Fundação Universidade Federal do Amazonas, Manaus, Amazonas. 107pp.

Moraes, J. C.; Costa, J. P. R.; Rocha, E. J. P.; Silva, I. M. O.1997. Estudos hidrometeorológicos na bacia do rio Caxiuanã. In: LISBOA, P. L. B. (Org.). Caxiuanã. Vol. 1. Museu Paraense Emílio Goeldi, Belém, Pará. p. 85-95.

Neto, T. A. C.; Pereira, M. G.; Correa, M. E. F.; Anjos, L.H.C. 2001. Deposição de liteira e mesofauna edáfica em áreas de eucalipto e floresta secundária. Floresta e Ambiente, Vol. 8, p. 70-75.

Novais, R. F.; Barros, N. F. 1997. Sustainable agriculture and forestry production systems on acid soils: phosphorus as a case study. In: Moniz, A. C. et al. (Eds.) Plant-soil interactions at low Ph: Sustainable agriculture and forestry productions. Campinas: Brazilian Soil Science Society, p. 314-320.

Olson, J. S. 1963. Energy storage and the balance of producers and decomposers in ecological systems. Ecology, Vol. 44, n. 2, p. 322-331.

Portes, M. C. G. O. ; Koehler, A.; Galvão, F. Variação Sazonal de deposição de liteira em uma Floresta Ombrófila densa Altomontana no morro do Anhangava. Floresta, Vol. 26, p. 3-10, 1996.

Sanchez-Alvarez, J.; Sada, S. G. 1993. Litterfall Dynamics in a Mexican Lowland Tropical Rain Forest. Tropical Ecology, Vol. 34, p. 127-142.

Silva, M.F.F. 1982. Produção anual de liteira e seu conteúdo mineralógico em mata tropical de terra firme na área do Rio Tocantins, Pará. Dissertação de Mestrado. Instituto Nacional de Pesquisas da Amazonia/Fundação Universidade Federal do Amazonas, Manaus, Amazonas. 78p.

SPSS for Windows. 1999. Release 10.0, Chicago: SPSS Inc. 
Teixeira, L.B., Oliveira, R.F. Martins, P. F. 2001. Ciclagem de nutrientes através da liteira em floresta, capoeira e consórcios com plantas perenes. Revista Ciências Agrárias, Vol. 36, p. 91-99.

Thornthwate, C. W. 1948. An approach towards a rational classification of climate. Geographycal Review, London, n. 38, p. 55-94.

Vianello, R. L.; Alves, A. R. 1991. Meteorologia básica e aplicações. Viçosa: Imprensa Universitária/Universidade Federal de Viçosa. $449 \mathrm{p}$.

Werneck, M. S.; Pedralli, G.; Gieseke, L. F. 2001. Produção de serrapilheira em trechos de uma floresta semidecídua com diferentes graus de perturbação na estação Ecológica do Tripuí, Ouro Preto-MG. Revista Brasileira de Botânica, Belo Horizonte, Minas Gerais. Vol. 24, n. 2, p. 195-198.

Recebido em 28/11/2007

Aceito em 23/06/2009 